\title{
Bioprosthesis in young patients: A reality or a fantasy
}

\author{
Farhang Yazdchi, MD, MS, Tsuyoshi Kaneko, MD, and Sary Aranki, MD
}

From the Division of Cardiac Surgery, Department of Surgery, Brigham and Women's Hospital, Harvard Medical School, Boston, Mass.

Disclosures: Authors have nothing to disclose with regard to commercial support.

Received for publication Aug 17, 2018; accepted for publication Aug 20, 2018; available ahead of print Oct 5, 2018.

Address for reprints: Sary Aranki, MD, Division of Cardiac Surgery, Brigham and Women's Hospital, 75 Francis St, Boston, MA 02115 (E-mail: saranki@partners.org).

J Thorac Cardiovasc Surg 2019;157:894-5

$0022-5223 / \$ 36.00$

Copyright (c) 2018 Published by Elsevier Inc. on behalf of The American Association for Thoracic Surgery https://doi.org/10.1016/j.jtcvs.2018.08.034

Scherman and colleagues report ${ }^{1}$ a retrospective study of 108 patients with rheumatic heart disease who underwent isolated first-time aortic valve replacement with mechanical valves and observed a significantly higher valve-related late mortality and thromboembolic/bleeding events compared with an age- and sex-matched population. The authors emphasize the lack of compelling evidence and associated guidelines to balance the risk of thromboembolic/bleeding events associated with mechanical valves against the risk of reoperation with bioprosthesis. This article highlights the ongoing discussion regarding the age threshold for the use of bioprosthesis.

This interesting study is one of few about mechanical aortic valve replacement for rheumatic heart disease that highlights the difficulties of anticoagulation and its adverse outcome. Amazingly, they managed to achieve 100\% follow up in this scattered "low-to middle-socioeconomic" status population during their mean follow-up time of 6 years, although the details of how this was accomplished was not specified in their article. In addition, the study did not include mitral valve replacements for rheumatic cases, which we suspect will be associated with even more valvular events (thromboembolism/bleeding).

The problem seems to be less of underlying pathology, valve choice, or socioeconomic status, but more the challenge of anticoagulation for any cause. It is known that keeping the international normalized ratio within the therapeutic range described by the term "time within therapeutic range" is a major challenge even in developed countries. In a randomized trial performed in North America, ${ }^{2}$ the international normalized ratio levels were within therapeutic range in only $32 \%$ of the time during the first 6 months of initiating warfarin. We can easily predict that the time within therapeutic range is lower in the developing countries, leading to even more bleeding/thrombotic complications.

We strongly agree that the patient's compliance with anticoagulation and socioeconomic environment described in this study should be considered when making decisions

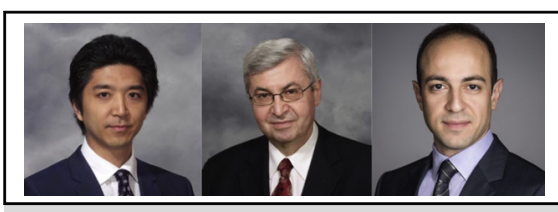

Tsuyoshi Kaneko, MD, Sary Aranki, MD, and Farhang Yazdchi, MD, MS

Central Message

Warfarin management is challenging because of wide deviation of time-in-therapeutic range. Evolving transcatheter technology may justify the use of bioprosthetic valves in younger patients.

See Article page 886 .

about valve choice. The only class I indication in 2014 American Heart Association/American College of Cardiology guidelines ${ }^{3}$ is that the choice of valve should be a shared decision process between the physician and the patient. A bioprosthetic valve is recommended in patients of any age for whom anticoagulant therapy is contraindicated, patients who cannot be managed appropriately, or anticoagulation is not desired. In other cases, the choice of valve is debatable, with no strong prescription by the guidelines. Patients with lower socioeconomic status solely rely on what their doctors choose for them. In the past, younger patients tend to favor mechanical prosthesis to avoid future reoperation. This trend has been changing in favor of bioprosthesis in United States in recent years. ${ }^{4,5}$ This is mainly driven by the desire to avoid anticoagulation and subsequent lifestyle change, and because of relatively low risk of reoperation, ${ }^{6}$ especially if the minimally invasive approach is used for the first operation, ${ }^{7}$ and the promising prospect of transcatheter valve-in-valve options. We predict that in the near future, aortic valve disease in younger patients will be treated with a surgical bioprosthesis as their first operation, especially when no other indication for anticoagulation exists. This will be followed by a transcatheter valve-in-valve procedure as their second or even third operation in the setting of structural valve deterioration. Surgical reoperation may be considered for patients with unfavorable anatomy, such as the risk of coronary obstruction or patient-prosthesis mismatch with the transcatheter procedure. The major hurdle to this strategy, especially in developing countries, will be the cost, although a patient's strong preference may overcome this. 


\section{References}

1. Scherman J, Manganyi R, Human P, Pennel T, Brooks A, Brink J, et al. Isolated mechanical aortic valve replacement in rheumatic patients in a low- to middleincome country. J Thorac Cardiovasc Surg. 2019;157:886-93.

2. Beyth RJ, Quinn L, Landefeld CS. A multicomponent intervention to prevent major bleeding complications in older patients receiving warfarin. A randomized, controlled trial. Ann Intern Med. 2000;133:687-95.

3. Nishimura RA, Otto CM, Bonow RO, Carabello BA, Erwin JP III, Guyton RA, et al. 2014 AHA/ACC guideline for the management of patients with valvular heart disease: a report of the American College of Cardiology/American Heart Association task force on practice guidelines. J Thorac Cardiovasc Surg. 2014;148: e1-132.

4. Brown JM, O'Brien SM, Wu C, Sikola JH, Griffith BP, Gammie JS. Isolated aortic valve replacement in North America comprising 108,687 patients in 10 years: changes in risks, valve types, and outcomes in the Society of Thoracic Surgeons national database. J Thorac Cardiovasc Surg. 2009;137:82-90.

5. Kaneko T, Aranki SF. No rat poison for me. J Thorac Cardiovasc Surg. 2017;154: 1542-3.

6. Kaneko T, Vassileva CM, Englum B, Kim S, Yammine M, Brennan M, et al. Contemporary outcomes of repeat aortic valve replacement: a benchmark for transcatheter valve-in-valve procedures. Ann Thorac Surg. 2015;100:1298-304.

7. Gosev I, Neely RC, Leacche M, McGurk S, Kaneko T, Zeljko D, et al. The impact of a minimally invasive approach on reoperative aortic valve replacement. J Heart Valve Dis. 2015;24:181-6. 